\title{
Silica inflammation modulates lipoperoxide and thiobarbituric acid reactive substances levels in liver and glucose concentration in blood of alloxan diabetic rats
}

\author{
Vyacheslav A. Shkurupiy, Natalya A. Palchikova*, Vera G. Selyatitskaya, Olga P. Makarova, \\ Natalya V. Kuznetsova, Olga I. Kuzminova \\ Siberian Branch of Russian Academy Medical Sciences, Scientific Centre of Clinical and Experimental Medicine, Novosibirsk, Rus- \\ sia; ${ }^{*}$ Corresponding Author: labend@mail.ru, labend@,soramn.ru \\ Received 6 September 2012; revised 12 October; accepted 9 November 2012
}

\section{ABSTRACT}

Inflammatory granulomatous diseases are characterized by a high concentration of granulomas in tissue interstitium in which phagocytic cells that produce active oxygen and nitrogen metabolites are accumulated. Because of their high reactivity, free radicals react with unsaturated fatty acids that are components of membrane phospholipids, activate lipid peroxidation processes (LPP), the products of which have a cytotoxic effect. The role of free radicals in the pathogenesis of diabetes and its complications has been proved. The purpose of the present work was to investigate the activity of lipid peroxidation processes in the liver of rats with silica-induced granulomatous inflammation, alloxan diabetes and their combination. The experiment involved male albino rats divided into four main groups. The first group were rats with silica granulomatous inflammation (SL rats); the second group were alloxan diabetic rats (DB rats); and the third group were alloxan diabetic rats, in which silica granulomatous inflammation was induced 8 days after the disease onset (DB_SL rats), the fourth group were rats that were injected saline physiological solution into the tail vein (control rats). Rats were withdrawn from the experiment within different time periods after the induction of pathological processes. LPP activity in liver homogenates was determined by the relative concentration of lipoperoxides in the heptane-isopropanol system and the concentration of products of the reaction with 2-thiobarbituric acid-reactive substances (TBARS). The severity of carbohydrate metabolism disorders was evaluated through the measurement of the blood level of glucose, daily urine volume and the relative weight of the kindneys. We found that silica administration activated LPP in the liver of SL rats; we observed the accumulation of primary products on day 1 after administration and later that of TBARS followed by normalization of their concentration by day 21 of the experiment. TBARS concentration was higher in DB rats than in the control at all stages of the experiment indicating the maintenance of high LPP activity in the liver of DB rats. TBARS concentration in the liver of DB_SL rats decreased by 3 times by the end of the experiment compared to DB rats, at the same time, they displayed a decreased blood glucose concentration, reduced diuresis and relative weight of the kidneys caused by hyperglycemia and associated polyuria. We conclude that one of the possible mechanisms of the influence on silica granulomatous inflammation on the course of alloxan diabetes can be 1) a reduced LPO activity in liver cells at the lates stages of granulomagenesis process induced by a single dose of a suspension of silica microparticles and 2) a combined decrease in glucose production in the liver of alloxan diabetics rats.

Keywords: Silica Granulomatous Inflammation; Alloxan Diabetic Rats; Liver Lipid Peroxidation; Blood Glucose

\section{INTRODUCTION}

Inflammatory granulomatous diseases are characterized by a high concentration of granulomas in tissue interstitium in which phagocytic cells producing reactive oxy- 
gen and nitrogen species (RONS) are accumulated [1-3]. Because of their high reactivity, free radicals react with unsaturated fatty acids that are components of membrane phospholipids, activate lipid peroxidation processes (LPP), the products of which have a cytotoxic effect [1].

Previously, other authors and we have shown that a large number of the so-called "non-immune" granulomas consisting mainly of monocytes and macrophages as well as epithelioid cells and a small number of neutrophils, lymphocytes and fibroblasts at the early stages (organ with a high concentration of resident macrophages) are formed in the liver staring from the first day after intravenous administration of a suspension of silica microparticles to experimental animals [4-6]. On day 3 after intravenous administration of silica micropartices, the state of vacuolar degeneration was observed in the liver of mice against the background of a large number of granulomas in $64 \%$ of hepatocytes, and $31 \%$ of hepatocytes were in a state of necrobiosis [6] i.e. RONS generated by macrophages and neutrophils of granulomas initiate hepatocyte damage.

Three or four weeks after intravenous administration of silica, a decrease in the proportion of neutrophils, macrophages and monocytes as well as an increased concentration of fibrous tissue were observed in granulomas [5], which coincides with decreased LPP activity in the liver [7]. The study of the destructive and reparative processes in mouse liver at chronic silica-induced granulomatous inflammation showed that the degree of fibrosis of the liver portal tracts rose with increasing time after silica administration $[6,8]$. Similar results are given in Kanta J. et.al. [4]. It is shown that 35 days after intravenous injection of silica, the formation of the capsules of connective tissue took place around granulomas with its propagation also inside granulomas, neither malondialdehyde concentration nor superoxide dismutase activity in the liver being increased.

The role of free radicals in the pathogenesis of diabetes mellitus (DM) and its complications is well-known $[1,9]$.

Increased production of free radicals at DM is due to chronic hyperglycemia, increased glucose autoxidation with the formation of ketoaldehyde and reactive oxygen compounds, non-enzymatic glycosylation of antioxidant protection enzymes $[10,11]$. The bioantioxidant systems of the organism are capable of inhibiting free radical oxidation of lipids. In a healthy organism, LPP activity and that of antioxidant protection systems are in a dynamic equilibrium. This equilibrium is disturbed in DM patients, and LPP activity exceeds the capacity of antioxidant systems $[12,13]$.

The changes in the activity of gluconeogenesis enzymes and increased hepatic glucose production are associated at diabetes just with increased LPP activity in the liver [14-16].

We have previously shown that the activity of aminotransferases contributing to the involvement of amino acids in gluconeogenesis reaction is increased in the liver of rats with severe alloxan diabetes [17,18]. It is unknown what LPP will be like after the induction of silica inflammation in animals with DM. This information is important because DM patients are highly susceptible to inflammatory diseases, and oxidative stress plays a significant role in the development of DM complications $[12,19]$.

The purpose of the present work was to investigate the activity of lipid peroxidation processes in liver of rats with silica-induced granulomatous inflammation, alloxan diabetes and their combination.

\section{MATERIALS AND METHODS}

\subsection{Experimental Animals, Diabetes Induction and Granulomatous Inflammation}

The work was performed on adult male Wistar rats obtained from the vivarium of the Institute of Cytology and Genetics SB RAS (Novosibirsk). The animals were kept in individual cages on the standard diet of the vivarium with free access to water and food.

The study was performed taking into account the basic principles of the Declaration of Helsinki (2000) and was approved by the local Committee on Biomedical Ethics of the Research Center of Clinical and Experimental Medicine, SB RAMS.

Experimental diabetes in rats was simulated by a single intraperitoneal injection of alloxan (Sigma) at a dose of $170 \mathrm{mg} / \mathrm{kg}$ of bodyweight after 18 hours of starvation.

Seven days after alloxan injection, daily urine was collected individually from each animal with special urine collectors, its volume and glucose concentration were measured, and the daily excretion of glucose was estimated. The subsequent study involved animals with the daily excretion of glucose of $1.0 \mathrm{~g} / \mathrm{day}$ or higher. As a result, the daily excretion of glucose in the group of alloxan diabetic rats selected for further study was $4.8 \pm$ $0.5 \mathrm{~g} /$ day vs. $0.004 \pm 0.001 \mathrm{~g} /$ day in intact rats.

To simulate granulomatous inflammation in rats, a suspension of $1-5-\mu \mathrm{m}$ silica microparticles S-563 (Sigma) at the dose of $100 \mathrm{mg} / \mathrm{kg}$ of bodyweight in physiological saline solution $(0.9 \% \mathrm{NaCl})$ was injected once into the lateral tail vein.

Four groups of experimental animals were prepared:

1) Silica granulomatous inflammation rats (SL rats);

2) Alloxan diabetic rats (DB rats);

3) Alloxan diabetics rats in which silica granulomatous inflammation was induced 8 days after the disease onset (DB_SL rats); 
4) Rats injected with physiological saline solution into the tail vein (control rats).

\subsection{Material Collection}

In the experimental dynamics, the daily urine was collected from rats in all the four groups, and diuresis was measured.

The bodyweight of each animal was determined. The animals were withdrawn from the experiment by decapitation. DB rats were withdrawn from the experiment 9, 12, 22, 29 days after alloxan administration; SL rats and DB_SL rats were withdrawn 1, 4, 14 and 21 days after silica administration. In DB SL rats, these terms corresponded to 9, 12, 22, 29 days after alloxan administration. There were at least 5 animals in the groups during all observation periods.

The weight of the kindneys was measured for each animal, and the relative weight of the organ per $100 \mathrm{~g}$ of bodyweight was calculated.

Serum glucose concentration was measured.

Samples of the right lobe of the liver were homogenized in physiological saline solution containing $0.1 \%$ EDTA. Liver homogenates were centrifuged (15 min at $4000 \mathrm{rev} / \mathrm{min}$ ), and the supernatant fractions were frozen at $18^{\circ} \mathrm{C}$ for further determination of LPO products in them.

\subsection{Determination of Biochemical Parameters}

Serum and urine glucose concentrations were determined by the enzymatic method using GLU kits (BioCon, Germany).

LPP activity in the liver was assessed by the content of primary intermediates in the system heptane-propanol and the concentration of secondary products - thiobarbituric acid-reactive substances (TBARS) in tissue homogenates [20,21]. The applied methodical approach allowed us to estimate changes in LPP activity in the dynamics of development of the studied pathologies.

The concentrations of primary intermediates in the liver homogenates were measured spectrophotometrically in the heptanoic phase of lipid extract at three wavelengths - 220, 232 and $278 \mathrm{~nm}$. The results were expressed as units of oxidation indices. Oxidation indices reflected the relative level of conjugated dienes $\left(\mathrm{E}_{232 / 220}\right)$ and ketodienes and conjugated trienes $\left(\mathrm{E}_{278 / 220}\right)$.

TBARS concentration in the liver homogenates was determined spectrophotometrically at the wavelength of $532 \mathrm{~nm}$ and expressed in $\mu \mathrm{mol} / \mathrm{kg}$, the molar extinction coefficient taken as equal to $1.56 \times 10^{-5} \mathrm{~mol}^{-1} \cdot \mathrm{cm}^{-1}$.

\subsection{Statistical Analysis}

Results were expressed as mean \pm SEM. Statistical differences were evaluated using the Kruskal-Wallis ANOVA test followed by the Mann-Whitney test [22]. All analyses were performed using the Statistica 6.0 application package (Statsoft, USA) Differences were considered statistically significant at $\mathrm{P}<0.05$.

\section{RESULTS}

\subsection{Evaluation of Lipid Peroxidation Processes Activity (Table 1)}

In SL rats, a day after silica administration, the con-In SL rats, a day after silica administration, the concentration of conjugated dienes in the liver increased by 1.9 times, that of ketodienes and conjugated trienes - by 1.4 times, and TBARS concentration increased by 1.5 times compared to the values of these indices of control rats.

On day 4 of inflammation, the concentration of LPO primary products decreased to smaller values than those of the control rats whereas TBARS concentration, on the contrary, increased by 2 times. On day 14 of inflammation, the concentration of primary products began to increase against the background of high TBARS concentration, and on day 21 the values of all the studied parameters returned to control levels.

In $\mathrm{DB}$ rats, the concentration of primary intermediates of LPP in the liver decreased 9 - 22 days after alloxan injection: that of conjugated dienes - by 1.5 times, and that of ketodienes and conjugated trienes-by 3.3 times compared to the values of these indices in control animals. In addition, these animals had an increased concentration of TBARS: it was 3.7 times higher than this index in control rats. By the end of the experiment (Day 29 of the disease), the concentration of conjugated dienes increased to the levels of control rats, and that of ketodienes and conjugated trienes increased almost 2-fold as compared to their values at early stages of the disease but remained below the control level.

TBARS concentration in the liver decreased by the end of the experiment, but it remained 2 times higher than the control level.

In DB_SL rats injected with silica 8 days after induction of alloxan diabetes, the dynamics of changes in the relative concentration of primary intermediates of LPP in liver homogenates were similar to the dynamics of changes in the values of the studied indices observed in SL rats.

Although TBARS concentration in DB rats on day 9 of diabetes was 3.7 times higher than the control level, in DB_SL rats during the same period of the disease it did not differ from the value of this index in the control rats. On day 12 of diabetes and, therefore, day 4 of inflammation, in DB_SL rats the summation of the effects of these pathological processes on LPO activity was revealed by 
Table 1. Concentration of primary and secondary LPO products in the rat's liver of different experimental groups $(\mathrm{M} \pm \mathrm{m})$.

\begin{tabular}{|c|c|c|c|c|c|}
\hline Experimental group & $\begin{array}{l}\text { Time after alloxan } \\
\text { administration } \\
\text { (days) }\end{array}$ & $\begin{array}{c}\text { Time after } \mathrm{SiO}_{2} \\
\text { administration } \\
\text { (days) }\end{array}$ & $\begin{array}{l}\text { Conjugated dienes } \\
\text { (oxidation indices) }\end{array}$ & $\begin{array}{l}\text { Ketodienes and } \\
\text { conjugated trienes } \\
\text { (oxidation indices) }\end{array}$ & $\begin{array}{l}\text { TBARS } \\
(\mathrm{nmol} / \mathrm{g})\end{array}$ \\
\hline \multirow{4}{*}{ SL rats } & - & 1 & $1.08 \pm 0.032^{\mathrm{a}}$ & $0.418 \pm 0.013^{\mathrm{a}}$ & $15.3 \pm 1.2^{\mathrm{a}}$ \\
\hline & - & 4 & $0.311 \pm 0.011$ & $0.078 \pm 0.006^{\mathrm{a}}$ & $32.0 \pm 2.4^{\mathrm{ad}}$ \\
\hline & - & 14 & $0.473 \pm 0.027$ & $0.103 \pm 0.007$ & $39.0 \pm 8.1$ \\
\hline & - & 21 & $0.588 \pm 0.015$ & $0.215 \pm 0.017$ & $14.5 \pm 3.5^{\mathrm{e}}$ \\
\hline \multirow{4}{*}{ DB rats } & 9 & - & $0.352 \pm 0.024^{\mathrm{a}}$ & $0.090 \pm 0.006^{\mathrm{a}}$ & $38.2 \pm 4.3^{\mathrm{a}}$ \\
\hline & 12 & - & $0.314 \pm 0.014^{\mathrm{a}}$ & $0.091 \pm 0.007^{\mathrm{a}}$ & $38.7 \pm 3.4^{\mathrm{a}}$ \\
\hline & 22 & - & $0.391 \pm 0.034^{\mathrm{a}}$ & $0.088 \pm 0.005^{\mathrm{a}}$ & $37.8 \pm 5.2^{\mathrm{a}}$ \\
\hline & 29 & - & $0.515 \pm 0.022$ & $0.160 \pm 0.007^{\mathrm{a}}$ & $23.3 \pm 4.5^{\mathrm{a}}$ \\
\hline \multirow{4}{*}{ DB_SL rats } & 9 & 1 & $1.049 \pm 0.194^{\mathrm{a}}$ & $0.341 \pm 0.048$ & $11.2 \pm 1.1$ \\
\hline & 12 & 4 & $0.306 \pm 0.011$ & $0.080 \pm 0.010$ & $54.6 \pm 7.0^{\mathrm{acd}}$ \\
\hline & 22 & 14 & $0.510 \pm 0.029$ & $0.137 \pm 0.014^{\mathrm{b}}$ & $43.0 \pm 7.7^{\mathrm{a}}$ \\
\hline & 29 & 21 & $0.583 \pm 0.017$ & $0.199 \pm 0.019^{\mathrm{b}}$ & $6.9 \pm 1.6^{\text {bce }}$ \\
\hline Control rats & - & - & $0.565 \pm 0.09$ & $0.296 \pm 0.008$ & $10.4 \pm 0.4$ \\
\hline
\end{tabular}

Differences are statistically significant: ${ }^{\mathrm{a}} \mathrm{P}<0.05$ compared to control rats; ${ }^{\mathrm{b}} \mathrm{P}<0.05$ compared to DB rats; ${ }^{\mathrm{c}} \mathrm{P}<0.05$ compared to SL rats; ${ }^{\mathrm{d}} \mathrm{P}<0.05$ compared to Day 1 for the rats of the same group; ${ }^{\mathrm{e}} \mathrm{P}<0.05$ compared to Day 4 for the rats of the same group.

TBARS concentration in liver homogenates. On day 22 of diabetes (14 days of inflammation) TBARS concentration in DB_SL rats began to decrease, though TBARS concentrations in DB rats and SL rats remained high during the same periods. At the final point of the experiment, TBARS concentration in DB_SL rats decreased below not only the values of the corresponding index in DB rats and SL rats (3.4-fold and 2.1-fold, respectively), but also below that of the control animals (by 1.5 times).

\subsection{Serum Glucose Concentration, Relative Weight of the Kidneys, the Daily Diuresis (Table 2)}

In SL rats, serum glucose concentration, the daily diuresis and the relative weight of the kidneys did not differ from the values of these indices in control rats.

In DB rats, serum glucose concentration was 4.5 times higher than that of control rats throughout the experiment. The value of the daily diuresis in these animals exceeded that in control rats by 6 times at the beginning of the experiment and by 11 times by the end of the experiment. Excretion of large amounts of fluid with urine was associated with an increase in the relative weight of the kidneys almost 2-fold as compared to the value of this index in control rats.

In DB_SL rats, the values of indicators of diabetes development 1 and 4 days after silica administration were similar to those of DB rats during the same period of the disease.

By the end of the experiment on days 22 and 29 of diabetes (14 and 21 days of inflammation), glucose level in serum of DB_SL rats decreased by 1.8 times as compared to the value of this index on day 9 of the disease in animals of this group. At the same time, no increase in daily urine was revealed in DB_SL rats, in contrast to DB rats, by the end of the experiment, and the relative weight of the kidneys of DB_SL rats 29 days after alloxan injection was lower by $24 \%$ compared to the value of this index of the DB rats.

\section{DISCUSSION}

Intravenous administration of silica activated LPP in the liver of healthy rats, and the accumulation of primary products was observed 1 day after the injection followed by that of secondary products such as TBARS, with the normalization of the concentrations of both primary and secondary LPO products 21 days after the induction of inflammation. The sharp increase in the concentrations of highly reactive LPO primary products in the liver of rats observed 1 day after silica administration may be probably due to the acute oxidative stress, which developed as a result of the capture of silica by macrophages and RONS production by activated macrophages $[2,3]$. The reduced activity of LPO in the liver after 21 days coincided with a decrease in the proportion of cells actively producing RONS-neutrophils, macrophages and mono- 
Table 2. Serum glucose concentration, relative weight of the kidneys and daily diuresis in rats of different experimental groups ( $\pm \mathrm{m})$.

\begin{tabular}{|c|c|c|c|c|c|}
\hline Experimental group & $\begin{array}{l}\text { Time after alloxan } \\
\text { administration } \\
\text { (days) }\end{array}$ & $\begin{array}{l}\text { Time after } \mathrm{SiO}_{2} \\
\text { administration } \\
\text { (days) }\end{array}$ & $\begin{array}{l}\text { Serum glucose } \\
\quad(\mathrm{mmol} / \mathrm{l})\end{array}$ & $\begin{array}{l}\text { Daily diuresis } \\
\text { (ml/day) }\end{array}$ & $\begin{array}{l}\text { Relative weight of } \\
\text { the kidneys } \\
\text { (g/100g BW) }\end{array}$ \\
\hline \multirow{4}{*}{ SL rats } & - & 1 & $6.4 \pm 0.3$ & $9 \pm 1$ & $0.64 \pm 0.02$ \\
\hline & - & 4 & $6.8 \pm 0.2$ & $10 \pm 1$ & $0.60 \pm 0.02$ \\
\hline & - & 14 & $6.9 \pm 0.4$ & $10 \pm 1$ & $0.60 \pm 0.02$ \\
\hline & - & 21 & $6.6 \pm 0.2$ & $10 \pm 1$ & $0.56 \pm 0.02$ \\
\hline \multirow{4}{*}{ DB rats } & 9 & - & $27.4 \pm 4.3^{\mathrm{ac}}$ & $58 \pm 11^{\text {ac }}$ & $1.16 \pm 0.06^{\mathrm{ac}}$ \\
\hline & 12 & - & $27.8 \pm 3.7^{\mathrm{ac}}$ & $75 \pm 19^{\mathrm{ac}}$ & $1.06 \pm 0.04^{\mathrm{ac}}$ \\
\hline & 22 & - & $27.3 \pm 4.3^{\mathrm{ac}}$ & $111 \pm 36^{\mathrm{ac}}$ & $1.12 \pm 0.08^{\mathrm{ac}}$ \\
\hline & 29 & - & $25.8 \pm 3.7^{\mathrm{ac}}$ & $101 \pm 6^{\text {ace }}$ & $1.18 \pm 0.08^{\mathrm{ac}}$ \\
\hline \multirow{4}{*}{ DB_SL rats } & 9 & 1 & $30.7 \pm 5.3^{\mathrm{ac}}$ & $53 \pm 13^{\text {ac }}$ & $1.02 \pm 0.08^{\mathrm{ac}}$ \\
\hline & 12 & 4 & $28.2 \pm 3.8^{\mathrm{ac}}$ & $64 \pm 13^{\mathrm{ac}}$ & $1.10 \pm 0.06^{\mathrm{ac}}$ \\
\hline & 22 & 14 & $17.0 \pm 2.4^{\text {acbd }}$ & $63 \pm 24^{\mathrm{ac}}$ & $1.00 \pm 0.08^{\mathrm{ac}}$ \\
\hline & 29 & 21 & $16.8 \pm 2.8^{\mathrm{acbd}}$ & $51 \pm 23^{\mathrm{ac}}$ & $0.90 \pm 0.08^{\text {acb }}$ \\
\hline Control rats & - & - & $6.2 \pm 0.1$ & $9 \pm 1$ & $0.60 \pm 0.02$ \\
\hline
\end{tabular}

Differences are statistically significant: ${ }^{\mathrm{a}} \mathrm{P}<0.05$ compared to control rats; ${ }^{\mathrm{b}} \mathrm{P}<0.05$ compared to DB rats; ${ }^{\mathrm{c}} \mathrm{P}<0.05$ compared to SL rats; ${ }^{\mathrm{d}} \mathrm{P}<0.05$ compared to Day 1 and 4 for the rats of the same group; ${ }^{\mathrm{e}} \mathrm{P}<0.05$ compared to Day 9 for the rats of the same group.

cytes - in the granulomas and an increase in the concentration of fibrous tissue in the liver. [5].

An important element of fibrogenesis in the liver is the production of growth factors, in particular, the transforming growth factor $\beta$, which stimulates the transformation of lipid-accumulating cells into fibroblasts [23]. The transforming growth factors $\beta 1, \beta 2$ and $\beta 3$ have a suppressor effect on RONS production by macrophages [24], which could reduce LPO activity in the liver, along with the death of macrophages that have captured silica microparticles [25].

The results of numerous works demonstrate an increased LPP activity in rats with alloxan and streptozotocin-induced diabetes [26,27]. They show increased TBARS concentration in plasm, liver, kidneys and other tissues of animals with experimental diabetes.

The decreased concentration of LPO primary products (conjugated dienes and trienes) in the liver of DB rats 9 days after alloxan injection could be associated with changes in the relationship between the oxidation rate of phospholipid membranes of hepatocytes, their composition and the number of substrates for the formation of conjugated dienes as well as a compensatory increase in the activity of antioxidant protection enzymes [28]. At the later stages of the experiment, the level of primary products reached control values whereas TBARS concentration remained higher than in the control, which indicated that LPP activity in the liver of DB rats remained high.
In DB_SL rats, the dynamics of changes in the concentration of LPO primary products in the liver was similar to those in SL rats. These results suggest that the timing of the capture of silica microparticles by macrophages and the accumulation of RONS-synthesizing activated macrophages in the liver are similar in rats of SL and DB_SL groups. However, the cause of decreased TBARS concentration in the liver of DB-SL rats 1 day after the induction of silica inflammation is not clear. The results substantiate the need for a detailed study of the activity of LPP and antioxidant defense systems in rats with diabetes and silica inflammation.

On day 12 of diabetes and, therefore, day 4 of inflammation, the summation of effects of these pathological processes on LPP activity was revealed by TBARS concentration in liver homogenates of DB_SL rats. At the later stages of the experiment, decreased TBARS concentration in liver homogenates below the control level was revealed in DB_SL animals. These findings reflect the phasic character of the accumulation of LPO products in the liver and in the manifestation of their possible negative effects at the organism level when diabetes is accompanied by granulomatous inflammation. This phasic character is probably determined by the dynamics of development of granulomatous inflammation.

A marked reduction of TBARS concentration in the liver of DB_SL rats by the end of the experiment was associated with a decrease in their blood glucose levels 
as well as lower diuresis and relative weight of the kidneys. Changes in the values of these three parameters indicate decreased hyperglycemia, associated polyuria and functional hypertrophy of the renal parenchyma. Our results are consistent with those of [29] where feeding alloxan diabetic mice an antioxidant-rich diet caused decreases in TBARS concentration in the liver and in the severity of hyperglycemia.

The effects of silica inflammation on diuresis and the relative weight of the kindneys in alloxan diabetic rats were not mediated by a direct damaging effect of silica on the kidneys as the induction of inflammation in SL rats did not cause any changes in the values of these indices as compared to control rats.

This may be associated with the absence of resident macrophages as granuloma formation centers in the kidneys and, consequently, granuloma macrophages capable of capturing silica and generating RONS in high concentrations thereby producing a cytotoxic effect. Large-scale destructive processes were observed in the liver where the concentration of resident macrophages and, consequently, granulomas at silica administration is high [6]. These data indicate a predominantly local (organ) character of the destructive effects of RONS generated by macrophages, in particular, by silicotic granuloma macrophages.

What are the possible mechanisms of the influence of silica-induced granulomatous inflammation on LPP activity in the liver of alloxan diabetic rats we have previously shown that silica-induced granulomatous inflammation is characterized by increased recruitment of monocytes from the bone marrow and their incorporation into granulomas during the first month after silica administration [2]. It can be supposed that the phenotype of the second generation of macrophages formed via differentiation of monocytes into them and the spectrum of the bioactive compounds synthesized by them differ from the corresponding characteristics of resident macrophages and the first generation of granuloma macrophage that have been lost after the capture of silica microparticles [25]. These newly formed macrophages second generation do not form a large quantity of RONS, which, in turn, together with increased production of growth factors (having a suppressive effect on RONS production by macrophages) at fibrogenesis [24] could promote the reduction of LPP activity in the liver of alloxan diabetic rats.

There may be other mechanisms that reduce the severity of hyperglycemia in rats with alloxan diabetes and silica inflammation. For example, the results obtained in $[30,31]$ indicate the generation of suppressor macrophages after BCG vaccination and suggest that these macrophages prevent the autoimmune pathogenesis leading to diabetes in NOD mice. The issues of potential use of immunomodulatory agents that may collectively be termed vaccines to prevent type 1 diabetes are discussed in [32]. However, problems of this type require special studies

\section{CONCLUSIONS}

These findings suggest that one of the possible mechanisms of the influence on silica granulomatous inflammation on the course of alloxan diabetes can be: 1) a reduced LPO activity in liver cells at the later stages of granulomagenesis process induced by a single dose of a suspension of silica microparticles; and 2) a combined decrease in glucose production in the liver of alloxan diabetic rats.

\section{REFERENCES}

[1] Valko, M., Leibfritz, D., Moncol, J., Cronin, M.T., Mazur, M. and Telser, J. (2007) Free radicals and antioxidants in normal physiological functions and human disease. The International Journal of Biochemistry and Cell Biology, 39, 44-84. doi:10.1016/j.biocel.2006.07.001

[2] Shkurupy, V.A., Nadeev, A.P., Karpov, M.A., and Bugrimova, Y.S. (2010) Experimental cytomorphological studies of the reaction of mononuclear phagocyte system in granulomatosis of mixed (silicotic and tuberculous) etiology. Bulletin of Experimental Biology and Medicine, 149, 462-465. doi:10.1007/s10517-010-0971-7

[3] Hamilton, R.F. Jr., Thakur, S.A. and Holian, A. (2008) Silica binding and toxicity in alveolar macrophages. Free Radical Biology and Medicine, 44, 1246-1258. doi:10.1016/j.freeradbiomed.2007.12.027

[4] Kanta, J., Horský, J., Kovárová, H., Tilser, I., Korolenko, T.A. and Bartoś, F. (1986) Formation of granulomas in liver of silica-treated rats. British Journal of Experimental Pathology, 67, 889-899. http://www.ncbi.nlm.nih.gov/pubmed/3099824

[5] Novikova, M.S., Potapova, O.V. and Shkurupy, V.A. (2008) Cytomorphological study of the development of fibrotic complications in chronic $\mathrm{SiO}_{2}$ granulomatosis in the liver during radon treatment. Bulletin of Experimental Biology and Medicine, 146, 279-282.

doi:10.1007/s10517-008-0280-6

[6] Skurupiy, V.A., Nadeev, A.P. and Karpov, M.A. (2010) Evaluation of destructive and reparative processes in the liver in experimental chronic granulomatosis of mixed (silicotic and tuberculous) etiology. Bulletin of Experimental Biology and Medicine, 149, 685-688. doi:10.1007/s10517-010-1024-y

[7] Makarova, O.P., Saperova, M.A. and Skurupiy, V.A. (2010) Lipid peroxidation in the liver and lungs in $\mathrm{SiO}_{2}$-induced granulomatosis. Bulletin of Experimental Biology and Medicine, 149, 702-705. doi:10.1007/s10517-010-1029-6

[8] Karpov, M.A., Skurupiy, V.A. and Nadeev, A.P. (2010) Analysis of fibrotic depositions in granulomas in chronic silicotuberculosis in mice. Bulletin of Experimental Biol- 
ogy and Medicine, 149, 659-662. doi:10.1007/s10517-010-1018-9

[9] Bachan, N., Kovsan, J., Kachko, I., Ovadia, H. and Rudich, A. (2009) Positive and negative regulation of insulin signaling by reactive oxygen and nitrogen species. Physiological Reviews, 89, 27-71. doi:10.1152/physrev.00014.2008

[10] Shams, M.E., Al-Gayyar, M.M. and Barakat, E.A. (2011) Type 2 diabetes mellitus-induced hyperglycemia in patients with NAFLD and normal LFTs: Relationship to lipid profile, oxidative stress and pro-inflammatory cytokines. Scientia Pharmaceutica, 79, 623-634. doi:10.3797/scipharm.1104-21

[11] Osawa, T. and Kato, Y. (2005) Protective role of antioxidative food factors in oxidative stress caused by hyperglycemia. Annals of the New York Academy of Sciences, 1043, 440-451. doi:10.1196/annals. 1333.050

[12] Vessby, J., Basu, S., Mohsen, R., Berne, C. and Vessby, B. (2002) Oxidative stress and antioxidant status in type 1 diabetes mellitus. Journal of Internal Medicine, 251, 69-76. doi:10.1046/j.1365-2796.2002.00927

[13] Jakus, V. (2000) The role of free radicals, oxidative stress and antioxidant systems in diabetic vascular disease. Bratislavské Lekárske Listy, 101, 541-551. http://www.ncbi.nlm.nih.gov/pubmed/11218944

[14] Jung, U.J., Lee, M.K., Park, Y.B., Jeon, S.M. and Choi, M.S. (2006) Antihyperglycemic and antioxidant properties of caffeic acid in $d b / d b$ mice. The Journal of Pharmacology and Experimental Therapeutics, 318, 476-483. doi:10.1124/jpet.106.105163

[15] Teimouri, F., Amirkabirian, N., Esmaily, H., Mohammadirad, A., Aliahmadi, A. and Abdollahi, M. (2006) Alteration of hepatic cells glucose metabolism as a non-cholinergic detoxication mechanism in counteracting diazinon-induced oxidative stress. Human and Experimental Toxicology, 25, 697-703. doi:10.1177/0960327106075064

[16] Singh, J. and Kakkar, P. (2009) Antihyperglycemic and antioxidant effect of Berberis aristata root extract and its role in regulating carbohydrate metabolism in diabetic rats. Journal of Ethnopharmacology, 123, 22-26. doi:10.1016/j.jep.2009.02.038

[17] Selyatitskaya V.G., Cherkasova O.P., Pankina T.V. and Palchikova N.A. (2008) Functional state of adrenocortical system in rats with manifest alloxan-induced diabetes mellitus. Bulletin of Experimental Biology and Medicine, 146, 708-710. doi: 10.1007/s10517-009-0393-6

[18] Selyatitskaya, V.G., Palchikova, N.A. and Kuznetsova, N.V. (2012) Adrenocortical system activity in alloxan-resistant and alloxan-susceptible Wistar rats. Journal of Diabetes Mellitus, 2, 165-169. doi: 10.4236/jdm.2012.22026

[19] Papanas, N., Zissimopoulos, A. and Maltezos, E. (2010) The role of nuclear medicine in the diagnosis of common and specific diabetic infections. Hellenic Journal of $\mathrm{Nu}$ clear Medicine, 13, 150-157. http://www.ncbi.nlm.nih.gov/pubmed/20808989

[20] Ohkawa, H., Ohishi, N. and Yagi, K. (1979) Assay for lipid peroxides in animal tissues by thiobarbituric acid reaction. Analytical Biochemistry, 95, 351-358. doi:10.1016/0003-2697(79)90738-3

[21] Volchegorsky, I.A., Dolgushin, I.I., Kolesnikov, O.L. and Tseilikman, V.E. (2000) Experimental modeling and laboratory evaluation of adaptive reactions of the organism. Publishers of the Chelyabinsk State Pedagogical University, Chelyabinsk.

[22] Glantz S. (1999) Primer of Biostatistics, Practica, Moscow.

[23] Dooley, S., Delvoux, B., Lahme, B., Mangasser-Stephan, K. and Gressner, A.M. (2000) Modulation of transforming growth factor beta response and signaling during transdifferentiation of rat hepatic stellate cells to myofibroblasts. Hepatology, 31, 1094-1106. doi: $10.1053 /$ he. 2000.6126

[24] Ding, A., Nathan, C.F., Graycar, J., Derynck, R., Stuehr, D.J. and Srimal, S. (1990) Macrophage deactivating factor and transforming growth factors-beta 1-beta 2 and -beta 3 inhibit induction of macrophage nitrogen oxide synthesis by IFN-gamma. Journal of Immunology, 145, 940-944.

[25] Pernis, B. (2005) Silica and the Immune System. Acta Bio-Medica: Atenei Parmensis, Suppl. 2, 38-44.

[26] Singh, S.N., Vats, P., Suri, S., Shyam, R., Kumria, M.M., Ranganathan, S. and Sridharan, K. (2001) Effect of an antidiabetic extract of Catharanthus roseus on enzymic activities in streptozotocin induced diabetic rats. Journal of Ethnopharmacology, 76, 269-277. doi:10.1016/S0378-8741(01)00254-9

[27] Sharma, N. and Garg, V. (2009) Antidiabetic and antioxidant potential of ethanolic extract of Butea monosperma leaves in alloxan-induced diabetic mice. Indian Journal of Biochemistry and Biophysics, 46, 99-105.

[28] Bliuger, A.F., Dudnik, L.B., Maĭore, A.I., Nozdrunova, N.A. and Mieze, I.E. (1985) Intensity of lipid peroxidation and its relation to changes in the composition and antioxidative properties of lipids in acute viral hepatitis. Voprosy Meditsinskoi Khimii, 31, 35-37.

[29] Park, N.-Y. and Lim, Y. (2011) Short term supplementation of dietary antioxidants selectively regulates the inflammatory responses during early cutaneous wound healing in diabetic mice. Nutrition and Metabolism, 8, 80-88. doi:10.1186/1743-7075-8-80

[30] Yagi, H., Matsumoto, M., Suzuki, S., Misaki, R., Suzuki, R., Makino, S. and Harada, M. (1991) Possible mechanism of the preventive effect of BCG against diabetes mellitus in NOD mouse. I. Generation of suppressor macrophages in spleen cells of BCG-vaccinated mice. Cellular Immunology, 138, 130-141. doi:10.1016/0008-8749(91)90138-2

[31] Yagi, H., Matsumoto, M., Kishimoto, Y., Makino, S. and Harada, M. (1991) Possible mechanism of the preventive effect of BCG against diabetes mellitus in NOD mouse. II. Suppression of pathogenesis by macrophage transfer from BCG-vaccinated mice. Cellular Immunology, 138, 142-149. doi:10.1016/0008-8749(91)90139-3

[32] Petrovsky, N., Silva, D. and Schatz, D.A. (2003) Vaccine therapies for the prevention of type 1 diabetes mellitus. Paediatric Drugs, 5, 575-582. doi:10.2165/00148581-200305090-00001 